\title{
Left ventricular to right atrial shunt (Gerbode defect): congenital versus acquired
}

\author{
Shi-Min Yuan \\ Department of Cardiothoracic Surgery, The First Hospital of Putian, Teaching Hospital, Fujian Medical University, China
}

Postep Kardiol Inter 2014; 10, 3 (37): 185-194

DOI: 10.5114/pwki.2014.45146

\begin{abstract}
A bstract
Introduction: Congenital left ventricular to right atrial (LV-RA) shunt (Gerbode defect) is rare, while acquired LV-RA shunt has been increasingly reported. As yet, systematically incorporated data of the LV-RA shunt have not been presented.

Aim: To present the clinical features, diagnostic challenge and management strategies of congenital and acquired LV-RA shunts.

Material and methods: The data source was based on a comprehensive literature retrieval of the LV-RA shunt in the period 1990-2013.

Results: In comparison with the acquired Gerbode defect, the congenital Gerbode defect group of patients were younger and were associated more often with additional congenital disorders. Previous cardiac surgery and infective endocarditis were the two major aetiologies of the occurrence of the acquired shunts. Paravalvular abscess was associated in $10.2 \%$ and atrioventricular block in $13.6 \%$ of the acquired group patients. Transoesophageal echocardiography showed a higher diagnostic accuracy, lower missed diagnosis and lower inclusive diagnosis rates, in comparison to transthoracic echocardiography, but the misdiagnosis rates of the two modalities did not differ from each other. Four (4.5\%) of the acquired group patients were complicated by atrioventricular block following surgical or interventional closure of the shunt. Eight (9.1\%) patients died in the acquired group, but no patient died in the congenital group.

Conclusions: The diagnosis of an LV-RA shunt is quite challenging, especially in the context of coexisting abnormalities including an additional intracardiac shunt, tricuspid regurgitation, pulmonary artery hypertension and infective endocarditis, which have to be carefully differentiated from the shunt by further investigations. A better control of infective complications and careful manoeuvres during surgery may help to keep the LV-RA-sensitive septum intact.
\end{abstract}

Key words: congenital heart defects, diagnostic errors, echocardiography, endocarditis, septal occluder device.

\section{Introduction}

The left ventricular to right atrial (LV-RA) shunt was firstly reported by Gerbode et al. [1] in 1958, and so the lesion was termed as the Gerbode defect. The left ventricular to right atrial shunts can be either congenital or acquired in nature. The term "Gerbode defect" should refer to the congenital rather than to the acquired shunt. Congenital LV-RA shunt is rare; however, acquired shunt has been increasingly reported as a result of infective endocarditis (IE), trauma, valve replacement, myocardial infarction, etc. [2]. The diagnosis of an LV-RA shunt is always challenging due to the limited diagnostic accuracy of transthoracic echocardiography (TTE). The remarkable misdiagnosis, missed diagnosis and inclusive diagnosis rates for this conventional non-invasive technique have made it less convincing as a diagnostic tool for a LV-RA shunt. Questions have been posed regarding the shortcomings of TTE and the potentially complementary alternatives for correct diagnosis. The coexistence of an alternative intracardiac shunt [3, 4], tricuspid regurgitation [5], pulmonary hypertension [6], etc. would make the diagnosis of an LV-RA shunt even more difficult. A delayed diagnosis may inevitably lead to worsening condition of the patient. Therefore, it is important to always bear in mind an LV-RA shunt when an unexplained turbulent flow is visualised in the right cardiac chamber, and further investigations by transoesophageal echocardiography (TEE), magnetic resonance imaging (MRI), computed tomographic angiography, etc. are warranted. Moreover, the predominant pathogenesis of the acquired LV-RA shunt, either postoperative or infective, was associated with considerable morbidity and mortality rates. A correct diagnosis and early treatment of the LV-RA shunt, particularly the

\section{Corresponding author:}

Prof. Shi-Min Yuan MD, PhD, Department of Cardiothoracic Surgery, The First Hospital of Putian, Teaching Hospital, Fujian Medical University, 389 Longdejing St, Chengxiang District, 351100 Putian (Fujian Province), China, phone: +86 1801201 8138, e-mail: shi_min_yuan@yahoo.com Received: 26.11.2013, accepted: 2.06.2014. 
acquired type, may lead to better clinical outcomes in such patients.

\section{Aim}

This study aims to present the clinical features, diagnostic challenge and management strategies of congenital and acquired LV-RA shunts.

\section{Material and methods}

A comprehensive literature retrieval was made in the PubMED database. The search terms included "Gerbode defect" and "LV-RA defect" with additional filters of "human" and "English" without year limit. A literature search of the Highwire Press, Google search engine and additional references cited in the articles completed the article collection. Atrial fistula and aorta-atrium fistula were primarily excluded from this study. The search ended on December 31, 2013.

The retrieval resulted in a collection of 111 articles [2-113], which included 77 (59.3\%) case reports [3, 5-7, 9, $12-14,16,17,19-23,25-28,30,33,35-37,39,42,44-54$, 57, 59-61, 63-67, 71, 76-80, 82, 84-89, 92-97, 99-107, 110-112] (including $8(7.4 \%)$ case reports in the name of "letter to the editor" $[5,25,26,30,79,84,92,111])$, $17(17.6 \%)$ medical images [2, 10, 11, 15, 22, 32, 40, 41, $43,58,69,70,72,74,98,108,109], 5(4.6 \%)$ case series $[8,18,34,38,73], 4(3.7 \%)$ original articles $[24,62,75$, 105], 2 (1.9\%) echo rounds [55, 91], 2 (1.9\%) "how-to-do's" $[68,81], 2(0.9 \%)$ conference abstracts $[56,90], 1(0.9 \%)$ quiz [4] and 1 (0.9\%) journal supplement abstract [31]. Exclusion criteria included duplicate publications in 3 [69, 91, 93], and a large cohort of LV-RA shunts with a disputable congenital or acquired aetiology and potentially considerable bias on the statistical analysis of the present paper [105], a "mirror-image" Gerbode defect [109] and an Ebstein's anomaly-associated Gerbode-like defect, which could be a real VSD in a format of Gerbode defect due to severe displacement of the septal tricuspid leaflet [29]. As a result, 104 articles regarding 121 patients with a LV-RA shunt were included in this study.

Diagnostic errors by echocardiography include misdiagnosis, missed diagnosis and inclusive diagnosis. A misdiagnosis is a diagnosis by echocardiography, which does not conform to the result of the definite diagnosis. A missed diagnosis, also called a false negative diagnosis, is when the shunt is not found by echocardiography but is disclosed by alternative diagnostic means. An inclusive diagnosis is when the shunt is visualised by echocardiography but the origin and nature of the shunt cannot be determined and other diagnostic approaches are required to confirm these.

\section{Statistical analysis}

Measurement data were expressed in mean \pm standard deviation with range and median values and were compared by independent sample t-test. Categorical variables were compared by Fisher exact test. A value of $p<0.05$ was considered statistically significant.

\section{Results}

\section{Patient information}

Aetiologies of the LV-RA shunts were congenital in $32(26.4 \%)$ cases $[6,7,9-28,30-32]$, acquired in 88 (72.7\%) cases $[2,3,7,8,18,31,33-68,70-90,92,94-104$, $106-108,110,111$ ] and unknown in 1 (0.8\%) patient [112], respectively. A significant difference was noted in the percentages between congenital and acquired LV-RA shunts $\left(\chi^{2}=52.3, p<0.0001\right)$.

Mean patients' age was $50.1 \pm 22.6$ years (range: 1 month-86 years; median 63 years) $(n=112)$. Of the patients whose gender could be tracked, there were 73 (62.4\%) males and 44 (37.6\%) females, with a maleto-female ratio of $1.66: 1$. A significant age difference was found between genders ( $53.3 \pm 21.2$ years vs. $43.8 \pm 24.7$ years, $p=0.0470$ ) and between patients with a congenital and an acquired LV-RA shunt ( $35.0 \pm 22.7$ years vs. 54.7 \pm 23.1 years, $p<0.0001$ ). There was no difference in the male-to-female ratio between congenital and acquired group patients (1.31 (16: 13) vs. 1.23 (56:31), $\chi^{2}=0.8$, $p=0.3770)$.

\section{Clinical characteristics}

Over $25 \%$ of the congenital and $21.3 \%$ of the acuired group patients were asymptomatic. The most common symptoms of the symptomatic patients were dyspnoea (7 patients (21.9\%) vs. 14 patients $(15.9 \%)$ ) and congestive heart failure (5 patients (15.6\%) vs. 13 patients (14.8\%)) in both groups. Fever (8 patients, 9.1\%) was a more common symptom in the acquired group patients. Aortic wall abscesses were seen in 9 patients (10.2\%) [33, 39, $40,53,55,58,78,87,104]$ and atrioventricular block in $12(13.6 \%)$ (2 were with aortic wall abscess [39, 61], 6 were third degree $[39,61,82,89,99,102]$ and 6 were first degree $[18,44,48,86,101,102])$ of the acquired group patients but in none in the congenital patients. There was significant dominance of right atrium dilation, right ventricle dilation, tricuspid regurgitation and pulmonary artery hypertension (Table I). The prevalence of right atrium dilation did not differ between the congenital and acquired groups (20/23 (87.0\%) vs. 23/31 (74.2\%), $\chi^{2}=1.3, p=0.2500$ ).

The underlying risk factors for the acquired LV-RA shunt can be divided into six categories: postoperative 52 (59.1\%) (including 39 (75\%) heart valve operations, 13 (25\%) congenital heart defect repair (1 patient had concurrent AVR and VSD repair) and 1 (1.9\%) ascending aorta replacement); infective 25 (28.4\%); ischaemic 5 (5.7\%); iatrogenic 4 (4.5\%); and traumatic 2 (2.3\%) (Figure 1).

The onset time of the acquired LV-RA shunt was reported in 51 patients. In 7 (13.7\%) patients, the LV-RA 
Table I. Comparisons of major cardiac structural and haemodynamic changes in relation to the left ventricular to right atrial shunt

\begin{tabular}{lcccc} 
Variable & Yes, $n(\%)$ & No, $n(\%)$ & $\chi^{2}$ & Value of $p$ \\
\hline Right atrial dilation $(n=54)$ & $40(74.1)$ & $14(25.9)$ & 25.0 & $<0.0001$ \\
\hline Right ventricular dilation $(n=31)$ & $22(71.0)$ & $9(29.0)$ & 19.9 & 0.0010 \\
\hline Tricuspid regurgitation $(n=32)$ & $27(84.4)$ & $5(15.6)$ & 30.3 & $<0.0001$ \\
\hline Pulmonary artery hypertension $(n=24)$ & $20(83.3)$ & $4(16.7)$ & 30.3 & $<0.0001$
\end{tabular}

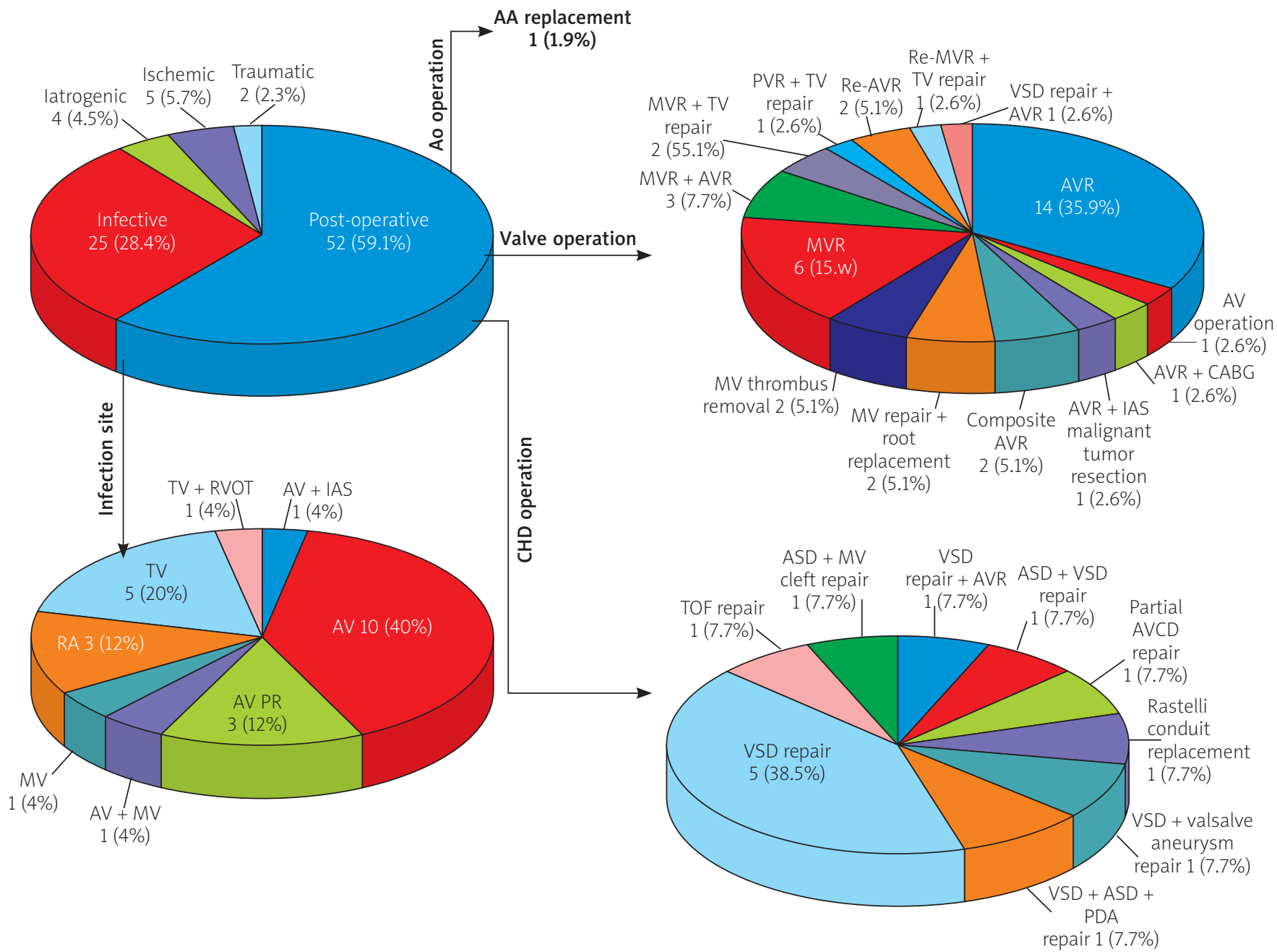

$A A$ - ascending aorta, $A 0$ - aorta, $A S D$ - atrial septal defect, AV-aortic valve, AVCD - atrioventricular canal defect, $A V R$ - aortic valve replacement, CABG - coronary artery bypass grafting, CHD - congenital heart defect, IAS - intra-atrial septum, MV-mitral valve, MVR - mitral valve replacement, PDA - patent ductus arteriosuS, $P R$ - prosthetic, PVR - pulmonary valve replacement, RA - right atrium, RVOT - right ventricular outflow tract, TOF - tetralogy of Fallot, TV - tricuspid valve, VSD ventricular septal defect

Figure 1. Distribution of aetiologies for acquired left ventricular to right atrial shunt

shunts developed immediately after cardiac interventions and the onset time was recorded as " 0 ". In general, the LV-RA shunts developed at $22.0 \pm 41.5$ (median: 2; range: $0-156)$ months $(n=51)$ after the cardiac operation, interventional therapy, or onset of IE.

There were 45 major heart valve operations including $26(57.8 \%)$ aortic, $18(40 \%)$ mitral and $1(2.2 \%)$ pulmonary valve operation. The indications for aortic valve operations were not described in 12 patients. Of the remain- ing 14 patients, 5 (35.7\%) patients were for IE, 4 (28.6\%) patients for rheumatic heart disease (aortic valve stenosis), 2 (14.3\%) for bicuspid aortic valve, 2 (14.3\%) for aortic dissection and 1 (7.1\%) was a redo-aortic valve replacement (AVR) for prosthetic aortic valve dysfunction (5 patients had concurrent AVR and mitral valve replacement and 1 patient had concurrent AVR and congenital VSD repair). Of the 18 patients with a mitral valve operation, the surgical indications were not stated in 4 patients. Of 
the remaining 14 patients, 6 (42.9\%) were for rheumatic heart disease (mitral valve stenosis), 3 (21.4\%) for mitral regurgitation (1 was mitral valve prolapse), 2 (14.3\%) for IE, 2 (14.3\%) were reoperations for prosthetic mitral valve thrombus clearance and 1 (7.1\%) for mitral valve cleft repair. The indication in the only patient for pulmonary valve replacement was IE. The frequencies of IE as an indication for a valve operation were $35.7 \%$ (5/14), 14.3\% $(2 / 14)$ and $100 \%(1 / 1)$ for aortic, mitral and pulmonary valve replacement, respectively. No significant difference was found between the former two frequencies $\left(\chi^{2}=1.7\right.$, $p=0.1900)$. Of the above 8 IE patients, the frequencies of aortic, mitral and pulmonary valve replacements represented $62.5 \%$ (5/8), $25 \%$ (2/8) and $12.5 \%$ (1/8), respectively. No significance was noted either between the former two $\left(\chi^{2}=2.3, p=0.1310\right)$ or between the three frequencies $\left(\chi^{2}=4.9, p=0.0870\right)$.

The IE was a direct cause of an acquired LV-RA shunt in 25 patients and was an indirect cause in 8 . In addition, 2 cases of remote IE (one of them was recurrent aortic valve IE following mitral IE) did not constitute the direct cause of a LV-RA shunt. Aortic valve IE was the most common in both direct and indirect causes of the LV-RA shunt. Tricuspid IE was a more common direct cause. Of all the patients of IE, the underlying pathogens were not indicated in 8 patients and no microorganism was shown by blood cultures in 3 patients (although one of them was shown as gram-positive cocci by histopathological inspections of the surgical specimens). In the remaining 22 patients, the pathogens were Staphylococcus in 12 (54.5\%) (11 S. aureus (2 each had methicillin-susceptible and methicillin-resistant $S$. aureus, 7 pathogen species were not stated and 1 S. epidermidis), 8 (36.4\%) Streptococcus ( 3 viridans, 2 mutans, 1 anginosous, $1 \alpha$-hemolyticus and 1 pneumonia), 1 (4.5\%) cardiobacterium hominis and 1 (4.5\%) non-typhoid salmonell) $\left(\chi^{2}=21.6\right.$, $p=0.0001)$.

The associated congenital anomalies in the congenital group patients included corrected transposition of the great arteries (1), patent ductus arteriosus + atrial septal defect + double orifice mitral valve (1), right aortic arch (1), atrial septal defect (1), atrial septal defect and VSD (1), subaortic valve membrane (1), cleft tricuspid valve (1), aneurysm of sinus Valsalva (1), patent ductus arteriosus (2) left superior vena cava (3), anomalous left hepatic vein (2) and congenital pericardial defect (1), giving a total of 16 (50\%) congenital heart defects. In comparison, the associated congenital anomalies in the acquired group patients were comprised of bicuspid aortic valve (6), patent fossa ovalis (3), aneurysm of sinus Valsalva (1), transposition of the great arteries + pulmonary atresia (1), left ventricle-coronary sinus fistula (1), atrial septal defect, VSD and patent ductus arteriosus (1), giving a total of 13 (14.8\%) cases as shown by echocardiography or magnetic resonance imaging (MRI). There was a significant differ- ence in the frequencies of associated congenital heart defects between the two groups $\left(\chi^{2}=6.4, p=0.0120\right)$.

\section{Diagnosis}

In one patient with unexpected sudden death, an LV-RA shunt was found incidentally at autopsy and in another 4 patients an LV-RA shunt was diagnosed by surgical exploration. The remaining 116 patients had a total of 248 diagnostic investigations performed. In 1 patient, diagnostic information for an LV-RA shunt by 3D TEE was not reported. Of the remaining 247 diagnostic images, TTE was the most commonly used method accounting for $55.1 \%$ of all diagnostic investigations, but showing limited diagnostic accuracy for $66.9 \%$ of cases. The TTE modes used in the diagnosis were colour Doppler 48 (64.9\%), 2-D echo 12 (16.2\%), continuous wave Doppler 13 (17.6\%) and pulsed Doppler 1 (1/4\%), respectively. Parasternal short axis and apical 4-chamber views were the most common views and colour Doppler imaging the most common mode for the diagnostic accuracy of TTE, but they were also the most common window and mode for inclusive diagnosis of intracardiac shunting locations. The subcostal 4-chamber images may provide the clearest view [18]. Pulsed Doppler and continuous Doppler mappings of TTE were less sensitive than colour Doppler in defining the shunt location. The TEE was the second most common technique for the diagnosis of LV-RA shunt, with a higher diagnostic accuracy $\left(\chi^{2}=15.2\right.$, $p<0.0001)$, lower missed diagnosis $\left(\chi^{2}=3.9, p=0.0490\right)$ and lower inclusive diagnosis rates $\left(\chi^{2}=7.0, p=0.0080\right)$ in comparison to TTE, but their misdiagnosis rates did not differ from each other $\left(\chi^{2}=1.8, p=0.1770\right)$. Alternative diagnostic techniques for confirming the LV-RA shunt were cardiac catheterisation, MRI, computed tomographic angiography, contrast echocardiography and radioisotope cardiac scan, etc.

The 11 misdiagnosed patients were initially mistaken as tricuspid regurgitation $[6,22]$ and tricuspid regurgitation and pulmonary artery hypertension $[25,83,84]$ in $3(27.3 \%)$ patients each and rupture of Valsalva aneurysm into the right atrium [14], prosthetic mitral valve leak [103], mitral valve regurgitation with prosthetic mitral valve leak [92], atrial septal defect [47] and residual VSD [8] in 1 (9.1\%) patient each. There were 45 TTE images leading to misdiagnosis, missed diagnosis, or inclusive diagnosis in 33 patients, whose correct diagnoses were established mostly by alternative diagnostic techniques, with TEE being the most frequent (Figure 2).

Shunting measurements were primarily carried out by cardiac catheterisation for the total pulmonary blood flow to total systemic blood flow ratio $(Q p / Q s)$, direct measurement during the operation, TTE and TEE for shunt size, and TTE for pressure gradient and flow velocity measurements. In 6 patients, the shunt size was measured with different techniques, with a larger result 


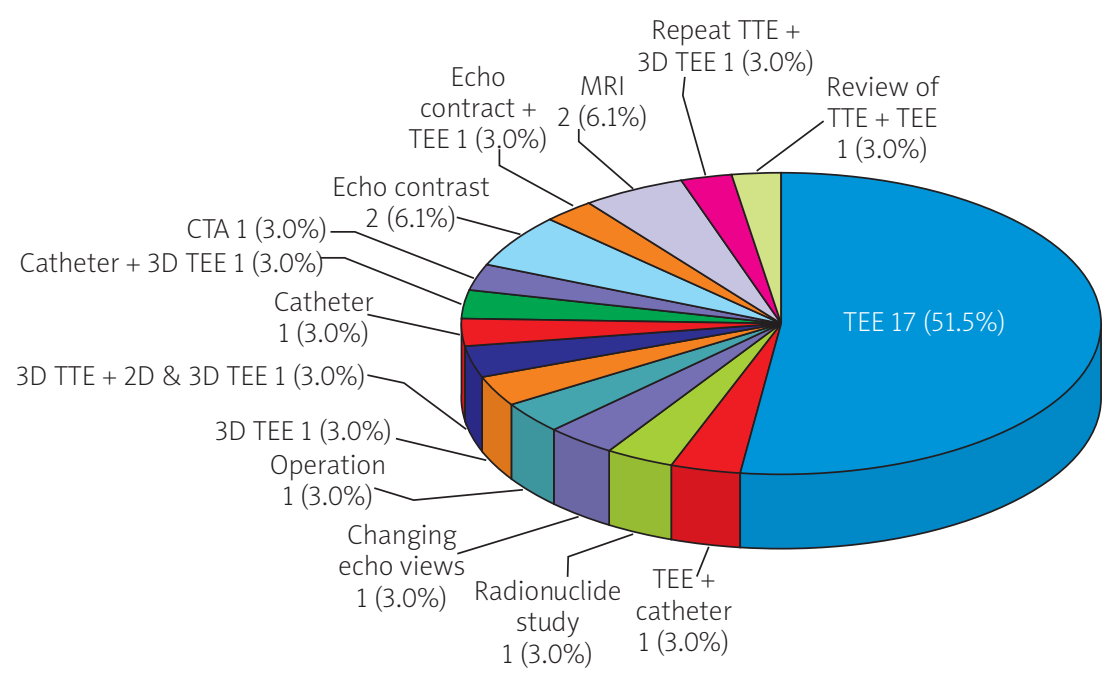

CTA - computed tomographic angiography, D - dimensional, MRI - magnetic resonance imaging, TEE - transoesophageal echocardiography, TTE - transthoracic echocardiography

Figure 2. Alternative diagnostic techniques for the correct diagnosis of the left ventricular to right atrial shunt in the 33 patients with a misdiagnosis, missed diagnosis, or inclusive diagnosis by transthoracic echocardiography

Table II. Management strategies for left ventricular to right atrial shunt

\begin{tabular}{|c|c|c|c|c|}
\hline Management & Congenital $(n=28)$ & Acquired $(n=82)$ & $\chi^{2}$ & Value of $p$ \\
\hline Surgical: & $19(67.9)$ & $54(65.9)$ & 0.0 & 0.8460 \\
\hline Patch repair & $6(21.4)$ & $22(26.8)$ & 0.5 & 0.4800 \\
\hline Pledgeted suture & $2(7.1)$ & $4(4.9)$ & 0.2 & 0.6700 \\
\hline Direct suture & $1(3.6)$ & $13(15.9)$ & 2.4 & 0.1240 \\
\hline Intraoperative device & $2(7.1)$ & $1(1.2)$ & 2.7 & 0.1010 \\
\hline Surgical technique not given & $8(28.6)$ & $14(17.1)$ & 1.7 & 0.1860 \\
\hline Associated cardiac operation & $5(17.9)$ & $28(34.1)$ & 3.7 & 0.0540 \\
\hline Interventional & $1(3.6)$ & $13(15.9)$ & 3.2 & 0.0730 \\
\hline Conservative & $1(3.6)$ & $1(1.2)$ & 0.6 & 0.4330 \\
\hline No treatment & $7(25)$ & $12(14.6)$ & 1.6 & 0.2120 \\
\hline Spontaneous closure & $0(0)$ & $2(2.4)$ & 0.7 & 0.3950 \\
\hline
\end{tabular}

by cardiac catheterisation than by TTE in 2 patients [85, 96] and by MRI than by TTE in 1 patient [12]. Shunt dimensions were smaller by direct measurement during the operation than by TTE [54]. Equal results were obtained between cardiac catheterisation and TTE [8] and between TTE and TEE [110] in one patient, each. Additionally, identical results of $Q p / Q$ s were obtained by non-invasive (MRI and TTE) and invasive measurements (cardiac catheterisation) in 2 patients $[25,26]$. Quantitative analysis did not reveal any intergroup differences in VSD size, $Q p / Q s$, peak velocity, pressure gradient across the VSD and pulmonary artery pressure.

\section{Management and prognosis}

No significant differences were noted in the patients subjected to different treatment strategies of surgical, interventional, conservative, no treatment, or spontaneous closure between congenital and acquired groups ( $\mathrm{Ta}$ ble II). The patients were on a follow-up of $12.6 \pm 10.8$ (range:
0.5-48; median: 11) months ( $n=32)$. No difference was present in the follow-up duration between the congenital and acquired groups (15.0 \pm 14.3 months vs. $12.3 \pm 10.4$ months, $p=0.6427)$. The overall morbidity and mortality were $7.3 \%(9 / 123)$ and $6.5 \%(8 / 123)$, respectively. Eight (9.1\%) patients from the acquired group had postoperative complications, including 4 (50\% of the complications and $4.5 \%$ of the group) atrioventricular block (3 following interventional therapy $[8,43,46]$ and 1 following surgical repair [104]), 2 (25\% of the complications and $2.3 \%$ of the group) residual shunts and 1 (12.5\% of the complications and $1.1 \%$ of the group) renal failure; whereas there was only 1 (3.1\%) postoperative complication: mild aortic and tricuspid valve insufficiency in the congenital group $\left(\chi^{2}=1.2, p=0.2730\right)$. Eight (9.1\%) patients died in the acquired group, while no patient died in the congenital group $\left(\chi^{2}=3.1, p=0.0770\right)$. In the acquired group, all 8 patients who dies had undergone surgical treatment, whereas none of the patients with interventional, con- 
servative, no treatment, or spontaneous closure died. A significant difference was discovered in the mortality rates between the surgical and non-surgical patients $\left(\chi^{2}=4.6, p=0.0320\right)$.

\section{Discussion}

Congenital LV-RA shunt is rare, accounting for $<1 \%$ of all congenital heart defects [55]. The mechanisms of the congenital LV-RA shunt from an embryologic viewpoint have not been fully described. The acquired LV-RA shunts may be caused by weakened membranous septum due to a previous operation [53], vegetation invasions of the membranous septum in IE [49], perforation of the upper portion of the membranous septum caused by an infection from IE in spite of the lack of vegetation [71], extended decalcification of the annulus in the posteromedial commissure or its vicinity during valve replacements [36, 51], or a tear in the tricuspid annulus at the membranous septum resulting in membranous septal injury [36].

Echocardiography was a gold standard for the diagnosis of the intracardiac shunts. However, the high velocity LV-RA jet may be misdiagnosed as tricuspid regurgitation with pulmonary artery hypertension [54, 83]. By echocardiography, the associated cardiac anomalies can be easily disclosed, whereas the VSD is sometimes be overlooked due to the dominance of the defect caused by the prosthesis in the aortic position [3]. Moreover, LV-RA shunts may display in several distinct anatomies on echocardiography, such as elongated sail-like [28], flap-like [38], a fistula form [85], a cystic thin walled structure [26], or a windsock-type tunnel appearance [8, 94], which make diagnosis difficult. To further define shunt anatomy and to quantify the shunt ratio, cardiac catheterisation and MRI are often advocated [74].

Pulsed wave Doppler is useful in localising the site of the intracardiac shunt by detecting a high-pitched audio signal and a turbulent as well as aliased flow velocity spectral display. Continuous wave Doppler can detect and measure peak systolic velocities across the shunt. Large defects are easily visualised by two-dimensional echocardiography and colour flow imaging may be used to localise small defects [114]. A $Q p / Q s$ ratio of $<1.5$ was typically suggestive of a small restrictive defect. When Qp/Qs was < $1.5: 1$, the cardiac chambers were usually not enlarged and the pulmonary vasculature was usually normal; whereas for large shunts with a $Q p / Q s>2.0: 1$, volume overload of the left atrium and left ventricle may develop with increased right ventricular and pulmonary arterial pressures [115].

Some authors [17, 97] have complained about the insensitivity of the parasternal, apical, or subcostal views of TTE for identifying the origin of the shunt. Desai et al. [19] reported that the parasternal long axis, parasternal short axis and apical four-chamber views were inadequate to demonstrate the exact location of the shunt and only revelaed a flow signal toward the tricuspid valve, mimicking tricuspid regurgitation. Dzwonczyk et al. [20] illustrated that 4-chamber view imaging could not determine the origin of the shunt, but a parastomal short-axis view could do this. Vallakati et al. [99] obtained a clear visualisation of the shunt with all views of TTE. The subcostal views (4-chamber or short-axis views) allow a clear visualisation as there is no bone or lung tissue to obstruct the view of the heart. The subcostal 4-chamber images show the clearest view of this defect $[18,80]$. Continuous wave and pulsed Doppler mappings of an LV-RA shunt are often misinterpreted as tricuspid regurgitation [3]. Differential diagnosis should also be made from a ruptured sinus of Valsalva or an endocardial cushion defect in parasternal short-axis and subcostal views [18]. With a high-velocity jet detected in the right atrium rather than in the right ventricle by colour Doppler, flow imaging can help the diagnosis of the LV-RA shunt [15]. The jet velocity of the LV-RA shunt can be different from that of the tricuspid regurgitation, with the shunt generating a significant higher jet velocity and probably a higher pressure gradient than tricuspid regurgitation on colour and continuous wave Doppler from the apical 4-chamber view [20]. Although, the shunt location could not be determined by cardiac catheterisation, the oxygen saturation gradient between the superior vena cava and the right atrium may confirm the existence of the shunt [47]. Visualisation by cardiac MRI of an intracardiac shunt with a high-velocity jet impinging on the anterior tricuspid leaflet during systole and bouncing back into the right atrium as tricuspid regurgitation can be helpful in the diagnosis of an LV-RA shunt [17]. When doubts arise concerning the pulmonary artery hypertension in association with an intracardiac shunt, cardiac catheterisation should be performed in order to rule out false pulmonary hypertension [25]. A to-and-fro flow by TEE could clearly demonstrate the shunt $[47,64]$. Furthermore, TEE guidance can be very useful in precisely locating the shunt and accurately measuring the distance from the defect to the aortic valve, thereby avoiding aortic valve entrapment during interventional management [46]. An LV-RA shunt should be suspected when there is an unusually dilated right atrium [35, 38, 46, 72, 101], the presence of an aortic root abscess or vegetations on the interatrial septum in the right atrium [33], or unexplained congestive heart failure $[24,64,93,103]$.

The present study revealed a dominance of right heart dilation, tricuspid regurgitation and pulmonary artery hypertension in patients with an LV-RA shunt of either congenital or acquired origin. The prevalence of right heart dilation did not differ between the two groups. As the diagnostic accuracy of TTE for the LV-RA shunt was $66.9 \%$, the remaining $33.1 \%$ of patients had to resort to other diagnostic methods, $51.5 \%$ of which were TEE. With limited information for comparisons of 
different ways to measure of the shunt size, TTE can detect shunt size more accurately in nearly half of the patients, as long as it locates the shunt position with proper views; while in the other half of the patients, the shunt size by TTE can be smaller than that detected by cardiac catheterisation by several millimetres. In this patient setting, the $Q p / Q s$ was detected by catheterisation in $27(77.1 \%)$ patients, by TTE in $6(15.8 \%)$ patients and by sporadically used techniques in 5 (13.2\%) patients, thereby representing convincing results. The statistical analysis for $Q p / Q s$ did not reveal a significant intergroup difference.

Paravalvular abscess and atrioventricular block can be complicated in the acquired rather than in the congenital patients, indicating that the complications may play a role, at least in part, in the formation of an LVRA shunt. The LV-RA shunt may often lead to very early and progressive congestive heart failure, usually within 6 months if left untreated properly [67]. Haemodynamic deterioration, a new LV-RA shunt and valvular destruction with ring abscess might be noted [87], so sometimes a surgical correction is warranted in these patients. However, Toprak et al. [96] recommended that patients with no symptoms and no right ventricular volume or pressure overload due to a small LV-RA shunt were not indicated for surgery but close follow-up was recommended instead. In the surgical operations, a patch repair should be performed on the right atrial side in order to prevent atrioventricular block [59, 94]. In long-term follow-up (up to 19.7 years) $17 \%$ of the LVRA shunts spontaneously closed, while $8.5 \%$ developed IE during follow-up [105]. The nature of spontaneous closure was proven, by surgical exploration, to be aneurysmal transformation of the tricuspid septal leaflet [58]. Patients with an acquired LV-RA shunt received interventional therapy with the use of the Amplatzer occluders to close the shunts, with satisfactory results. The mortality rates of surgically treated patients were much higher than for non-surgically treated patients, probably because the surgical patients had more severe illnesses, such as aortic wall abscess, for which they were indicated for a surgical operation.

\section{Conclusions}

Congenital LV-RA shunt is rare; however, acquired LVRA shunt has been increasingly reported. The diagnosis of an LV-RA shunt is quite challenging, especially when there are coexisted abnormalities such as an additional intracardiac shunt, tricuspid regurgitation, pulmonary artery hypertension and infective endocarditis, which have to be carefully differentiated from the shunt by further precise investigational techniques. A better control of infective complications and careful manoeuvres during surgery may help to keep the LV-RA-sensitive septum intact.

\section{References}

1. Gerbode F, Hultgren H, Melrose D, et al. Syndrome of left ventricular-right atrial shunt: successful surgical repair of defect in five cases with observation of bradycardia on closure. Ann Surg 1958; 148: 433-6.

2. Demirkol S, Gurkan Yesil F, Bozlar U, et al. Multimodality imaging of a congenital Gerbode defect. Kardiol Pol 2013; 71: 104.

3. Kelle AM, Young L, Kaushal S, et al. The Gerbode defect: the significance of a left ventricular to right atrial shunt. Cardiol Young 2009; 19 Suppl 2: 96-9.

4. Okamura T, Nagase Y, Mitsui F, et al. Left ventricular-right atrial communication complicated by aortic regurgitation. Asian Cardiovasc Thorac Ann 2008; 16: e1-3.

5. Sun X, Yang C, Zhou G, et al. Acquired left ventricular-right atrial communication following mitral valve replacement. J Heart Valve Dis 2010; 19: 801-2.

6. Weinrich $M$, Graeter TP, Langer F, et al. Left ventricular-right atrial fistula complicating redo mitral valve replacement. Ann Thorac Surg 2001; 71: 343-5.

7. Kautzner J, Munclinger MJ, Kozáková M. Acquired left ventricular-right atrial and right ventricular communication due to infective endocarditis after aortic valve replacement. Am Heart J 1990; 120: 1233-4.

8. Brili SV, Barberis VI, Karamitros IA, et al. Mild cyanosis due to coexistence of congenitally corrected transposition of the great arteries and Gerbode-type defect. Cardiology 2006; 105: 41-2.

9. Dragicevic N, Schmidlin E, Hazelton TR, et al. Gerbode ventricular septal defect diagnosed using cardiac CTA imaging. Radiol Case Rep 2011; 6: 1-3.

10. Sinisalo J, Sreeram N, Qureshi SA. Transcatheter closure of acquired left ventricle to right atrium shunts. Catheter Cardiovasc Interv 2013; 82: E809-14.

11. Acar P, Séguela PE, Hascoet S. The Gerbode defect or left ventricular to right atrial shunt assessed by transthoracic 3D echocardiography. Echocardiography 2011; 28: E140-2.

12. Agoston I, Esquivel-Avila J, Ahmad M. Live three dimensional echocardiography in evaluation of left ventricular to right atrial shunt (Gerbode defect). Heart 2006; 92: 1562.

13. Akpınar I, Karabağ T, Sayın MR, et al. An unusual defect and a rare combination: Gerbode defect and subaortic membrane. Anadolu Kardiyol Derg 2013; 13: E7-8.

14. Blanco AA, Haddy S, Baker CJ. Perimembranous ventricular septal defect and Gerbode defect. Echocardiography 2010; 27: 215-7.

15. Cheema OM, Patel AA, Chang SM, et al. Gerbode ventricular septal defect diagnosed at cardiac MR imaging: case report. Radiology 2009; 252: 50-2.

16. Coelho R, Pannu HS, Thakurta SG, et al. Ruptured aneurysm sinus of Valsalva and Gerbode defect with severe tricuspid and aortic regurgitation. A case report and its surgical correction. J Cardiovasc Surg (Torino) 1997; 38: 531-3.

17. Colomba D, Cardillo M, Raffa A, et al. A hidden echocardiographic pitfall: the Gerbode defect. Intern Emerg Med 2014; 9: 237-8.

18. Deng X, Li X, Li J, et al. A rare case of Gerbode defect associated with double orifice mitral valve. Thorac Cardiovasc Surg 2010; 58: 372-4.

19. Desai RV, Seghatol-Eslami F, Nabavizadeh F, et al. Unusual mechanism of tricuspid regurgitation in ventricular septal defect. Echocardiography 2011; 28: E36-8.

20. Dzwonczyk T, Davidson WR Jr. The spectrum of left ventricular-right atrial communications in the adult: essentials of echocardiographic assessment. J Am Soc Echocardiogr 1995; 8: 263-9. 
21. Erdöl C, Gökçe M, Celik S, et al. Two-dimensional color Doppler echocardiographic imaging of a Gerbode defect: a case report. Echocardiography 2000; 17: 335-6.

22. Eroglu S, Sade E, Bozbas H, et al. Echocardiographic diagnosis of left ventricular-right atrial communication (Gerbode-type defect) in an adult with chronic renal failure: a case report. Eur J Echocardiogr 2008; 9: 314-5.

23. Haponiuk I, Chojnicki M, Jaworski R, et al. Congenital pericardial defect with Gerbode type septal defect in rotated heart: report of a case. Kardiochir Torakochir Pol 2010; 7: 276-9.

24. Gościniak P, Larysz B, Baraniak J, et al. The Gerbode defect a frequent echocardiographic pitfall. Kardiol Pol 2012; 70: 1191-3.

25. Komai H, Naito Y, Fujiwara K, et al. An unusual variation of left ventricular-right atrial communication. Surg Today 1996; 26: 825-7.

26. Millan R, Pericas P, Forteza JF, et al. Real-time three-dimensional transesophageal echocardiography of the Gerbode defect. Int J Cardiol 2012; 157: e52-3.

27. Müller UM, Pittl U, Leontyev S, et al. Gerbode ventricular septum defect covered by a ballooning membranous ventricular septum. Clin Res Cardiol 2013; 102: 245-7.

28. Panduranga P, Mukhaini M. A rare type of Gerbode defect. Echocardiography 2011; 28: E118-20.

29. Patra S, Shankarappa RK, Karur S, et al. A Gerbode-like defect associated with Ebstein's anomaly in an adult patient. BMJ Case Rep 2013: 2013 pii: bcr-2013-200721. doi: 10.1136/bcr-2013200721.

30. Tacoy G, Oner Y, Cengel A. Transesophageal echocardiographic appearance and magnetic resonance imaging of a rare congenital heart disease: Gerbode defect. Ther Adv Cardiovasc Dis 2011; 5: 87-8.

31. Tehrani F, Movahed MR. How to prevent echocardiographic misinterpretation of Gerbode type defect as pulmonary arterial hypertension. Eur J Echocardiogr 2007; 8: 494-7.

32. Xin W, Hong T. GW24-e3091: The perioperative role of the echocardiography in left ventricular-right atrium shunt (Gerbode defect). Heart 2013; 99: A265. doi:10.1136/heartjnl-2013-304613.748.

33. Ying ZQ, Chen MY. Gerbode-type defect. Arch Cardiovasc Dis 2013; 106: 238-9.

34. Alphonso N, Dhital K, Chambers J, et al. Gerbode's defect resulting from infective endocarditis. Eur J Cardiothorac Surg 2003; 23: $844-6$

35. Álvarez JAG, Alonso JL, Leiva GA, et al. Unconventional applications of endovascular devices in acquired structural cardiopathies. Rev Argent Cardiol 2013; 81: 147-51.

36. Amirghofran AA, Emaminia A. Left ventricular-right atrial communication (Gerbode-type defect) following mitral valve replacement. J Card Surg 2009; 24: 474-6.

37. Aoyagi S, Arinaga K, Oda T, et al. Left ventricular-right atrial communication following tricuspid annuloplasty. Eur J Cardiothorac Surg 2008; 34: 680-1.

38. Battin M, Fong LV, Monro JL. Gerbode ventricular septal defect following endocarditis. Eur J Cardiothorac Surg 1991; 5: 613-4.

39. Benisty J, Roller M, Sahar G, et al. Iatrogenic left ventricular-right atrial fistula following mitral valve replacement and tricuspid annuloplasty: diagnosis by transthoracic and transesophageal echocardiography. J Heart Valve Dis 2000; 9: 732-5.

40. Bergman R, Natour E, Wang A, et al. A Gerbode-like defect after infective endocarditis. Anesth Analg 2013; 116 (SCA Suppl): $1-182$.
41. Bochard-Villanueva B, Fabregat-Andrés O, Estornell-Erill J, et al. Gerbode-type left ventricular outflow tract to right atrial fistula complicating prosthetic aortic valve replacement identified by cardiac computed tomographic angiography. J Cardiovasc Comput Tomogr 2012; 6: 355-6.

42. Can I, Krueger K, Chandrashekar Y, et al. Images in cardiovascular medicine. Gerbode-type defect induced by catheter ablation of the atrioventricular node. Circulation 2009; 119: e553-6.

43. Carpenter RJ, Price GD, Boswell GE, et al. Gerbode defect with Staphylococcus lugdunensis native tricuspid valve infective endocarditis. J Card Surg 2012; 27: 316-20.

44. Chaturvedi A, Lau R, Kicska G, et al. MR findings in iatrogenic Gerbode defect. Int J Cardiovasc Imaging 2013; 29: 3-4.

45. Cortez-Dias N, Varela MG, Marques J, et al. Acquired left ventricular-to-right atrial shunt (Gerbode defect) due to infective endocarditis. Rev Port Cardiol 2009; 28: 735-9.

46. Dadkhah R, Friart A, Leclerc JL, et al. Uncommon acquired Gerbode defect (left ventricular to right atrial communication) following a tricuspid annuloplasty without concomitant mitral surgery. Eur J Echocardiogr 2009; 10: 579-81.

47. Dangol A, Bansal M, Al-Khatib Y. Transcatheter closure of acquired left ventricle-to-right atrium shunt: first case report in an infant and review of the literature. Pediatr Cardiol 2013; 34: 1258-60.

48. Doig JC, Au J, Dark JH, et al. Post-infarction communication between a left ventricular aneurysm and the right atrium. Eur Heart J 1992; 13: 1006-7.

49. Dores H, Abecasis J, Ribeiras R, et al. Uncommon acquired Gerbode defect following extensive bicuspid aortic valve endocarditis. Cardiovasc Ultrasound 2012; 10: 7.

50. Elian D, Di Segni E, Kaplinsky E, et al. Acquired left ventricular-right atrial communication caused by infective endocarditis detected by transesophageal echocardiography: case report and review of the literature. J Am Soc Echocardiogr 1995; 8: 108-10.

51. Elmistekawy E, Dickie S, Nicholson D, et al. Left ventricular outflow tract-right atrial fistula following aortic valve replacement. J Card Surg 2012; 27: 570-2.

52. Frigg C, Cassina T, Siclari F, et al. Unusual complication after aortic valve replacement. Interact Cardiovasc Thorac Surg 2008; 7 : 149-50.

53. Garg R, Garcia R, Cubeddu RJ. Gerbode defect misinterpreted as pulmonary hypertension. J Cardiol Cases 2013; 7: e34-6.

54. Gorki H, Loulmet DF, Lessnau KD. A postoperative Gerbode defect in aortic prosthesis endocarditis with non-typhoid Salmonella. J Heart Valve Dis 2009; 18: 325-6.

55. Hansalia S, Manda J, Pothineni KR, et al. Usefulness of live/real time three-dimensional transthoracic echocardiography in diagnosing acquired left ventricular-right atrial communication misdiagnosed as severe pulmonary hypertension by two-dimensional transthoracic echocardiography. Echocardiography 2009; 26: 224-7.

56. Hilberath JN, Shook D, Shernan SK, et al. Left ventricular outflow tract to right atrial fistula diagnosed by intraoperative transesophageal echocardiography. Anesth Analg 2007; 104: 261-2.

57. Holy EW, Hufschmid U, Friedli BC. Acquired Gerbode defect following valve-sparing surgical repair of acute aortic type A dissection. Rare cardiac emergencies and other rarities: clinical cases part II, Freitag, 14. Juni 2013, 11:00-11:15. http://registration. akm.ch/einsicht.php?XNABSTRACT_ID=172973\&XNSPRACHE_ $I D=1 \& X N K O N G R E S S \_I D=188 \& X N M A S K E N \_I D=900$. 
58. Hori D, Tanaka M, Yamaguchi A, et al. Surgically treated infective endocarditis involving the aortic bicuspid valve and ventricular septum revealing aortic regurgitation and a Gerbode defect. Gen Thorac Cardiovasc Surg 2010; 58: 255-9.

59. Hsu SY, Shen TC. A spontaneously closed, acquired supravalvular Gerbode defect mimicking an unruptured sinus of Valsalva aneurysm. Eur Heart J Cardiovasc Imaging 2014; 15: 471.

60. Inoue $\mathrm{H}$, Iguro $\mathrm{Y}$, Kinjo $\mathrm{T}$, et al. Acquired left ventricular-right atrial communication and severe aortic valve regurgitation caused by infective endocarditis. Thorac Cardiovasc Surg 2009; 57: 54-6.

61. Jobic Y, Verdun F, Guillo P, et al. Postinfarction atrioventricular septal rupture. J Am Soc Echocardiogr 1997; 10: 680-4.

62. Joyce ES, McCarthy PM, Stewart WJ, et al. Left ventricular to right atrial fistula after aortic homograft replacement for endocarditis. Eur J Cardiothorac Surg 1994; 8: 100-2.

63. Karaci AR, Aydemir NA, Harmandar B, et al. Surgical treatment of infective valve endocarditis in children with congenital heart disease. J Card Surg 2012; 27: 93-8.

64. Katta S, Akosah K, Stambler B, et al. Atrioventricular fistula: an unusual complication of endomyocardial biopsy in a heart transplant recipient. J Am Soc Echocardiogr 1994; 7: 405-9.

65. Katz ES, Tunick PA, Kronzon I. To-and-fro left ventricular-to-right atrial shunting after valve replacement shown by transesophageal echocardiography. Am Heart J 1991; 121: 211-4.

66. Kumar PA, Sale S, Arora H, et al. Acquired "Gerbode-like" defect in aortic valve endocarditis: an imposter for tricuspid regurgitation? J Cardiothorac Vasc Anesth 2011; 25: 751-2.

67. Lax D, Bhatt RD, Klewer SE, et al. Are all ventricular septal defects created equal? J Am Soc Echocardiogr 2010; 23: 791.e5-7.

68. Lee SY, Song JY, Baek JS. Percutaneous closure of the acquired gerbode shunt using the amplatzer duct occluder in a 3-month old patient. Korean Circ J 2013; 43: 429-31.

69. Lorber A, Nair P, Gruberg L. Transcatheter closure of acquired Gerbode defect following mitral valve replacement using the Amplatzer duct occluder. J Invasive Cardiol 2006; 18: E264-6.

70. Matt P, Winkler B, Carrel T, et al. Plicated patch repair for acquired Gerbode defect involving the tricuspid valve. Ann Thorac Surg 2010; 89: 643-5.

71. Matt P, Winkler B, Gutmann M, et al. Acquired Gerbode defect after endocarditis. Eur J Cardiothorac Surg 2009; 36: 402.

72. Mendoza DD, Wang Z, Gaglia MA, et al. Gerbode defect. J Cardiovasc Comput Tomogr 2009; 3: 279-81.

73. Michel C, Rabinovitch MA, Huynh T. Sinus node dysfunction as a complication of Gerbode's defect associated with acute infective endocarditis. Heart 1996; 76: 379.

74. Moaref AR, Aslani A, Zamirian M, et al. Left ventricular to right atrial communication (Gerbode-type defect) after mitral valve replacement. J Am Soc Echocardiogr 2008; 21: 408.e1-2.

75. Mohapatra S, Minhas HS, Virmani S, et al. Acquired left atrial-to-right ventricular shunt with mitral valve incompetence: a rare sequela after repair of atrioventricular septal defect. Tex Heart Inst J 2009; 36: 69-71.

76. Mousavi N, Shook DC, Kilcullen N, et al. Multimodality imaging of a Gerbode defect. Circulation 2012; 126: e1-2.

77. Nathan M, Rimmer D, del Nido PJ, et al. Aortic atresia or severe left ventricular outflow tract obstruction with ventricular septal defect: results of primary biventricular repair in neonates. Ann Thorac Surg 2006; 82: 2227-32.

78. Neuss M, Meyhofer J, Butter C. Interventional closure of a postoperative left ventricular, right atrial fistula. EuroPCR Case
Corner: Interactive Case Corner 25 http://www.pcronline. com/Lectures/2012/EuroPCR-Case-Corner/Interventional-closure-of-a-postoperative-left-ventricular-right-atrial-fistula.

79. Newman JN Jr, Rozanski L, Kreulen T. Acquired left ventricular to right atrial intracardiac shunt after myocardial infarction: a case report and review of the literature. J Am Soc Echocardiogr 1996; 9: 716-20.

80. Ota T, Yamaguchi R, Tanigawa T, et al. Left ventricular-right atrial communication by perforation of the atrioventricular portion of the membranous septum and severe aortic valve regurgitation caused by infective endocarditis: J Echocardiogr 2011; 9: 30-2.

81. Ozdogan O, Cinar CS. Left ventricle-right atrium communication along with a membranous septum aneurysm. J Cardiovasc Med (Hagerstown) 2012; 13: 597-9.

82. Ozeke O, Celik E, Grbovic E, et al. Delayed left ventricular-to-right atrial communication (acquired Gerbode defect) after aortic valve replacement. Herz 2013 Oct 17. [Epub ahead of print].

83. Pillai V, Menon S, Kottayil B, Karunakaran J. Tricuspid endocarditis with indirect Gerbode: septal translocation of posterior leaflet. Heart Lung Circ 2011; 20: 362-4.

84. Portet N, Riu B, Bounes V, et al. Left ventricular-right atrial communication with third-degree atrioventricular block after thoracic trauma. J Emerg Med 2012; 43: e385-8.

85. Pursnani AK, Tabaksblat $M$, Saric $M$, et al. Acquired Gerbode defect after aortic valve replacement. J Am Coll Cardiol 2010; 55: e145.

86. Raja Y, Jenkins N, Chauhan A, et al. Acquired post-infarct Gerbode defect complicated by infective endocarditis with giant right atrial vegetation. Int J Cardiol 2006; 113: E79-80.

87. Rothman A, Galindo A, Channick R, et al. Amplatzer device closure of a tortuous Gerbode (left ventricle-to-right atrium) defect complicated by transient hemolysis in an octogenarian. J Invasive Cardiol 2008; 20: E273-6.

88. Saiki Y, Kawase M, Ida T, et al. The successful surgical repair of a left ventricular-right atrial communication and aneurysm of the mitral valve caused by infective endocarditis: report of a case. Surg Today 1994; 24: 655-8.

89. Scully RE, Mark EJ, McNeely WF, et al. Case records of the Massachusetts General Hospital. Weekly clinicopathological exercises. Case 34-1998. New Engl J Med 1998; 393: 1457-65.

90. Sharma AK, Chander R, Singh JP. AV nodal ablation-induced Gerbode defect (LV-RA Shunt). J Cardiovasc Electrophysiol 2011; 22: 1288-9.

91. Shen WK, Khandheria BK. Transesophageal echocardiography: detection of an acquired left ventricular-right atrial shunt. J Am Soc Echocardiogr 1991; 4: 199-202.

92. Shih R, Shook D, Mousavi N, et al. [-59] Diagnosis and management of acquired gerbode defect after reoperative aortic valve. http://www.scahq.org/sca3/events/2012/annual/syllabus/submissions/postersandabstracts/SCA-59.pdf.

93. Silbiger JJ, Kamran M, Handwerker S, et al. The Gerbode defect: left ventricular to right atrial communication-anatomic, hemodynamic, and echocardiographic features. Echocardiography 2009; 26: 993-8.

94. Sun X, Yang C, Zhou G, et al. Acquired left ventricular-right atrial communication following mitral valve replacement. J Heart Valve Dis 2010; 19: 676-7.

95. Tatewaki H, Alesnik J, Morales D. Acquired left ventricle to right atrial shunt (Gerbode defect) and massive pulmonary embolus. http://www.ctsnet.org/sections/clinicalresources/clinicalcases/ article-14. 
96. Toprak C, Kahveci G, Akpinar S, et al. Concomitant gerbode-like defect and anterior mitral leaflet perforation after aortic valve replacement for endocarditis. Echocardiography 2013; 30: E231-5.

97. Trehan V, Ramakrishnan S, Goyal NK. Successful device closure of an acquired Gerbode defect. Catheter Cardiovasc Interv 2006; 68: 942-5.

98. Uslu N, Kayacioglu I, Ates M, et al. 'Acquired' left ventricular to right atrial shunt after mitral valve replacement: detection by transthoracic colour Doppler echocardiography. Can J Cardiol 2007; 23: 735-6.

99. Vallakati A, Nerella N, Lodha A, et al. Unusual presentation of Gerbode defect. Tex Heart Inst J 2012; 39: 446-7.

100. Velebit V, Schöneberger A, Ciaroni S, et al. "Acquired” left ventricular-to-right atrial shunt (Gerbode defect) after bacterial endocarditis. Tex Heart Inst J 1995; 22: 100-2.

101. Venkatesh G, Lonn EM, Holder DA, et al. Acquired left ventricular to right atrial communication and complete heart block following nonpenetrating cardiac trauma. Can J Cardiol 1996; 12: 349-52.

102. Wasserman SM, Fann J, Atwood JE, et al. Acquired left ventricular-right atrial communication: Gerbode-type defect. Echocardiography 2002; 19: 67-72.

103. Watanabe A, Kazui T, Tsukamoto M, et al. Left ventricular pseudoaneurysm and intracardiac fistulas after replacement of mitral valve prosthesis. Ann Thorac Surg 1993; 55: 1236-9.

104. Winslow TM, Friar DA, Larson AW, et al. A rare complication of aortic valve endocarditis: diagnosis with transesophageal echocardiography. J Am Soc Echocardiogr 1995; 8: 546-50.

105. Wu MH, Wang JK, Lin MT, et al. Ventricular septal defect with secondary left ventricular-to-right atrial shunt is associated with a higher risk for infective endocarditis and a lower late chance of closure. Pediatrics 2006; 117: e262-7.

106. Xhabija N, Prifti E, Allajbeu I, et al. Gerbode defect following endocarditis and misinterpreted as severe pulmonary arterial hypertension. Cardiovasc Ultrasound 2010; 8: 44.

107. Yared K, Solis J, Passeri J, et al. Three-dimensional echocardiographic assessment of acquired left ventricular to right atrial shunt (Gerbode defect). J Am Soc Echocardiogr 2009; 22: 435.e1-3.

108. Yurdakul S, Tayyareci Y, Sezgiç M, et al. Case images: acquired Gerbode type ventricular septal defect after aortic valve replacement. Turk Kardiyol Dern Ars 2012; 40: 471.

109. Zacharkiw LA, Stimpson HL. Mirror-image Gerbode defect? Eur J Echocardiogr 2011; 12: 627.

110. Zhu D, Liu B, Tang H. Intraoperative device closure of acquired left ventricular-right atrium shunt in a pediatric patient with pulmonary hypertension. J Card Surg 2012; 27: 235-7.

111. Primus C, Grabscheit G, Ng CK, et al. Unusual cause of dyspnoea: a case presentation of an echocardiographic pitfall. J Cardiothorac Surg 2013; 8: 230.

112. Patanè S, Marte F, Di Bella G. Echocardiographic diagnosis of syndrome of left ventricular-right atrial shunt (Gerbode defect). Int J Cardiol 2008; 128: e85-6.

113. Silverman NA, Sethi GK, Scott SM. Acquired left ventricular-right atrial fistula following aortic valve replacement. Ann Thorac Surg 1980; 30: 482-6.

114. Reeder GS, Currie PJ, Hagler DJ, et al. Use of Doppler techniques (continuous-wave, pulsed-wave, and color flow imaging) in the noninvasive hemodynamic assessment of congenital heart disease. Mayo Clin Proc 1986; 61: 725-44.

115. Rajiah P, Kanne JP. Cardiac MRI: Part 1, cardiovascular shunts. AJR Am J Roentgenol 2011; 197: W603-20. 